\title{
Modeling and Simulation of Current Ripple in DC Link Connecting two PWM Inverters Using Matlab/Simulink
}

\author{
Taufik $^{(1)}$, and Makbul Anwari ${ }^{(2)}$ \\ (1) Electrical Engineering Department \\ Cal Poly State University \\ San Luis Obispo, CA 93407 USA \\ taufik@calpoly.edu \\ (2) Department of Energy Conversion \\ Universiti of Teknologi Malaysia \\ Skudai, Malaysia \\ makbul@ieee.org
}

\begin{abstract}
In this paper, the impacts of PWM carrier signals to DC bus current ripple in a PWM-based GeneratorLoad system will be investigated. The study is crucial to aid in the determination of the dc bus capacitor in a real-world inverter system. A Simulink model depicting the contribution of the generator current and the load current to the total DC bus current will be described. Results of the computer simulations will also be discussed.
\end{abstract}

\section{Introduction}

In today's energy conservative world, power electronics has become ever increasingly important. The widespread use of power electronics can now be found from the low power-end devices, such as those used in hand-held devices, to the high-powered Flexible AC Transmission Controllers (FACTS) installed to improve the operation of transmission and distribution lines [1]. In the US alone by the end of the year 2010 , approximately $80 \%$ of electrical loads were power electronics driven [2]. The number was most likely more in other parts of the world. Another field which has also been impacted significantly by the advance in power electronics is the distributed or backup generation system. With the promise of a highly efficient generation system for commercial, residential, and industrial system, power electronics has unavoidably become an integral part of modern generators used in backup or stand-alone source of electric power.

In distributed generation, several approaches to provide the generation has been implemented and currently being marketed and used in different parts of the world. Examples of this would be the Photovoltaic (PV) or Solar Panels, Fuel Cell system, Diesel generator, and Microturbine generator, to name a few.
Some of these techniques such as the Microturbine and PV system make use of power electronics to generate electricity in a useful form. Since modern electrical loads have increasingly implemented power electronics, it is then not an uncommon situation to have power electronic-based generator, such as a microturbine generator, connected to a power electronic-driven load, such as Adjustable Speed Drives. In such a case, it will be very important to study the interaction between the two power electronic systems so that proper operation and prevention of any possible failure can be guaranteed.

The power electronic-based generator-load system previously mentioned is typically one in which the generator produces ac, while the load might be a dc or ac load. A very widely known technique to produce an ac signal is through what is called the Pulse Width Modulation technique or PWM for short. Although the ac output of the PWM scheme resembles that of a sinusoidal waveform, it unfortunately consists of unwanted harmonics. On the output stage, the ac output of the generator is basically interfaced with the PWM of the ac load through a dc link known as the dc bus. This dc bus is mainly a large capacitor that is capable of handling harmonic currents from both the generator and the load. In this paper, modeling and simulation of the power-electronic-based generatorload system will be described to study the effect of having two PWM sytems on the dc bus capacitor. Results of the study will be useful and important in properly sizing the dc bus capacitor which further implies cost saving.

\section{Basic Block Diagram}

Figure 1 shows the simplified block diagram of the generator-load system with a de link or bus. Currents $\mathrm{I}_{\text {gen }}$ and $\mathrm{I}_{\text {load }}$ are resulted from the two modulating PWM inverters inside the load and generator. The 
PWMs utilize triangular waveform as reference signal whose switching frequency is fixed. The objective of the study is then to investigate the effect on the dc bus or capacitor $\left(\mathrm{I}_{\text {cap }}\right)$ current ripple due to the PWMs. In particular, the characteristics of the ripple under the condition where one PWM triangular signal is phase shifted with respect to the other will be discussed. Furthermore, the effect of changing the modulation ratio of the PWM to the dc bus current ripple will also be discussed.

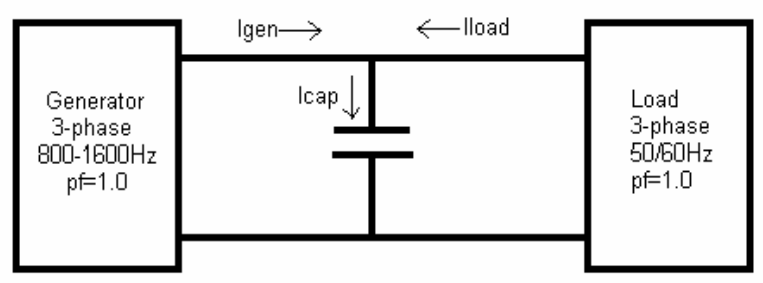

Figure 1. Generator-Load Block Diagram

\section{Ripple Current and Triangle Generator}

The dc bus current $\mathrm{I}_{\text {cap }}$ consists of dc average value $\mathrm{I}_{\mathrm{dc}}$ and ac switching frequency $\mathrm{I}_{\mathrm{ac}}$ components as described by the following equation:

$$
I_{c a p}=\sqrt{I_{d c}^{2}+I_{a c}^{2}}
$$

The ac component $I_{a c}$ is the one responsible for the ripple current which may be determined from the FFT (Fast Fourier Transform) of the dc bus current and then applying the following equation:

$$
I_{\text {acripple }}=\sqrt{\sum_{h=2}^{\infty} I_{h}^{2}}
$$

The parameter $I_{h}$ is the harmonic components of the dc bus current. Note that harmonic component number 1 is eliminated from above calculation since it is none other than the fundamental component.

Matlab/Simulink was chosen to model and simulate the generator-load system. First, the PWM triangular waveform was created using Matlab m script file. The script file will generate two separate triangular waveforms for the two inverters used in the model with phase shifting capability. An example with $45^{\circ}$ out of phase shift is illustrated on Figure 2.

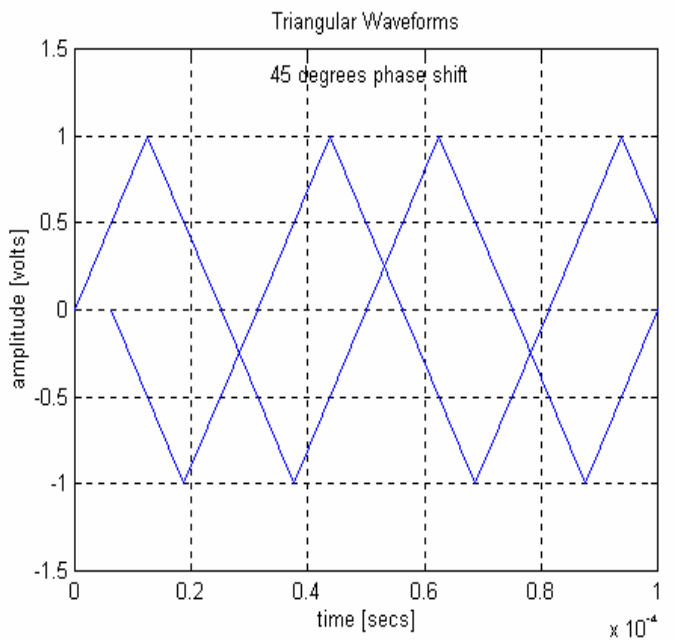

Figure 2. Matlab generated phase-shifted triangular waveforms for load and generator's PWM inverters

\section{Phase-Shift Effect on Ripple Current}

To see the effect of phase shifting one PWM signal with respect to the other, a Simulink block diagram was developed as shown on Figure 3. The previous matlab script that produces the triangular waveforms provides one input to the block diagram. The results of the Simulink diagram are further processed through another Matlab $\mathrm{m}$ script file to compute their corresponding Fourier components. Once this process is done, the dc bus ripple current may then be computed using (2).

In-phase and out-of-phase shifts were consequently introduced to the triangle waveform generator script. In the simulation, power factors of both sides were assumed to be 1.0, modulation index of both PWM's were at 1.0, load frequency $60 \mathrm{~Hz}$, generator frequency at $1600 \mathrm{~Hz}$, switching frequency of both inverters is $20 \mathrm{kHz}$, while keeping the fundamental current reference at $120 \mathrm{~A}$. The results are plotted in Figure 4 where it shows that in-phase and out-of-phase configurations yield approximately the same ripple currents. More importantly, it also shows that introducing a phase shift of $\pm 90^{\circ}$ will result in the maximum ripple current.

\section{Current Ripple Factor $K_{t}$}

To study the behavior of the dc bus current ripple; a new constant $\mathrm{K}_{\mathrm{t}}$ is defined below for convenience:

$$
K_{t}=\frac{I_{\text {cap }(\text { rms })}}{I_{\text {acout }(\text { peak })}}=\frac{I_{\text {ripple(rms })}}{I_{\text {acout }(\text { peak })}}
$$




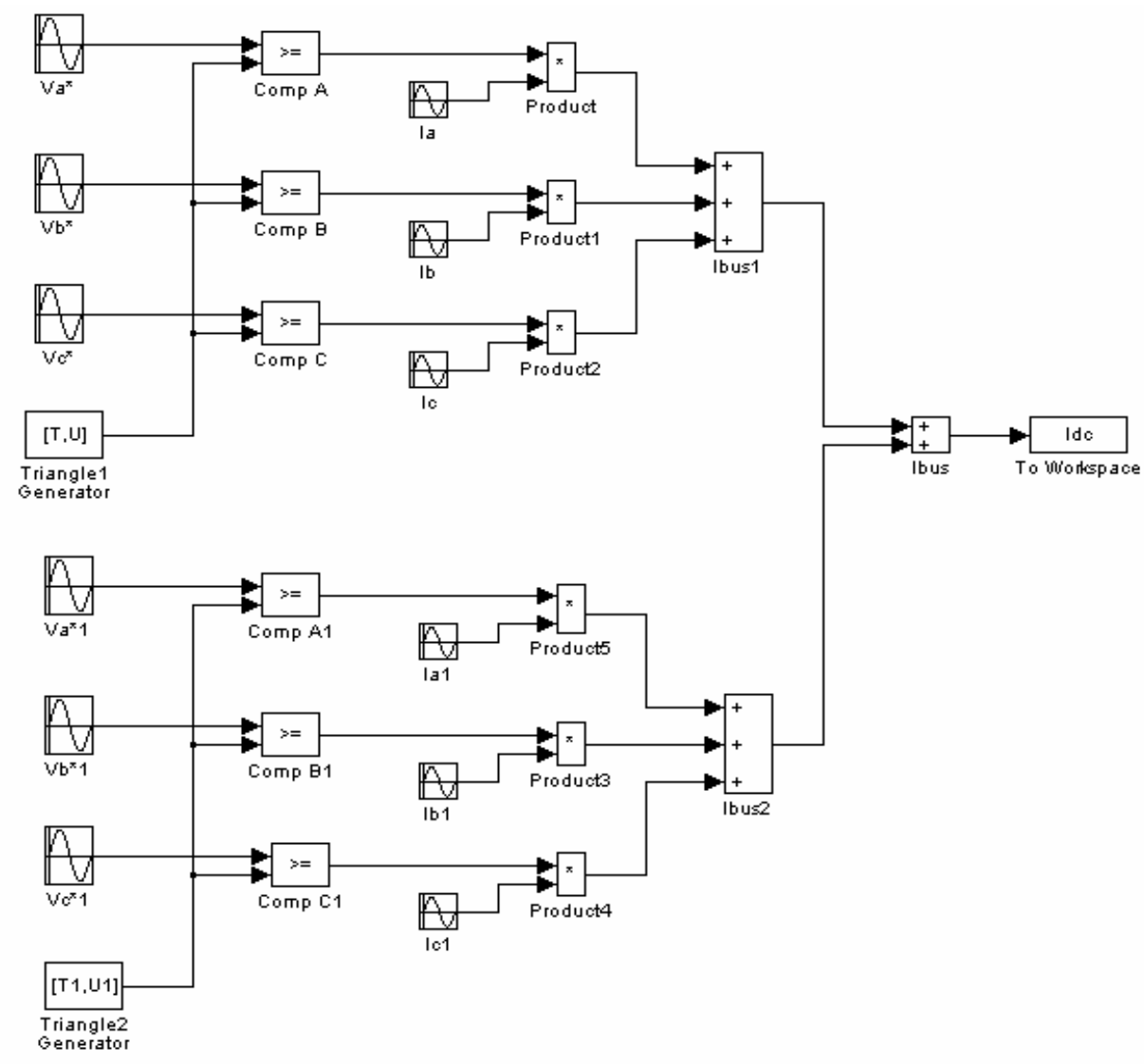

Figure 3. Simulink block diagram for DC bus current ripple

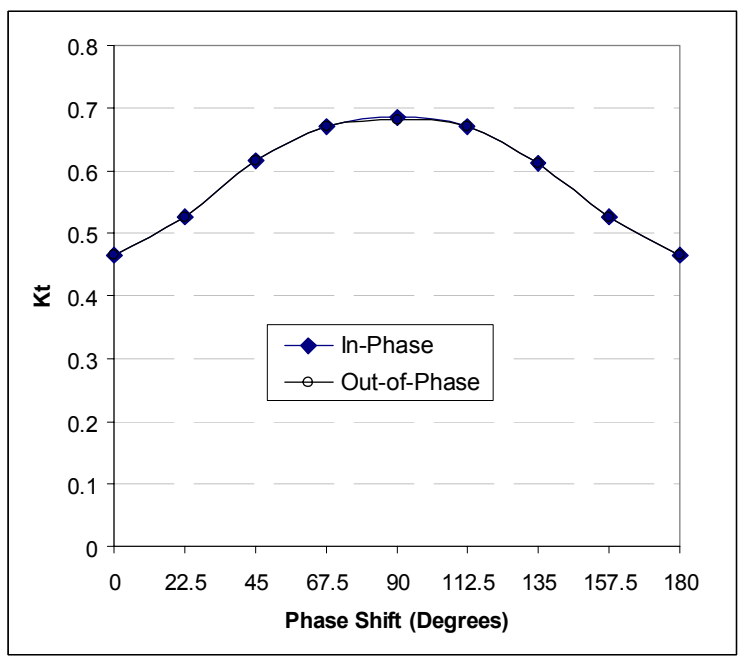

Figure 4. Shift effects on DC bus ripple current rms

The newly defined constant $\mathrm{K}_{\mathrm{t}}$ depends on both the modulation index $\left(\mathrm{M}_{\mathrm{i}}\right)$ and the switching frequency ratio $\left(\mathrm{S}_{\mathrm{fr}}\right)$ of the PWM's. Thus, it will be very useful to generate plots to see how $\mathrm{K}_{\mathrm{t}}$ behaves as the modulation index and switching frequency are varied. As illustrated in Figure 5, $\mathrm{K}_{\mathrm{t}}$ and thus the rms current ripple reaches its maximum value when the modulation index is at 0.6 with the assumption that the output current is kept constant. However, in a typical real system, the relationship between frequency and modulation index and output current is typically described as follows:

Table 1. Frequency and Modulation Indices

\begin{tabular}{|l|l|}
\hline Generator side & Load side \\
\hline $\mathrm{M}_{\mathrm{i}} \propto \omega$ & $\mathrm{M}_{\mathrm{i}}=\mathrm{M}_{\mathrm{L}}$ \\
\hline $\mathrm{I}_{\text {gen }} \propto \omega$ & $\mathrm{I}_{\mathrm{Load}} \propto\left(1 / \mathrm{M}_{\mathrm{L}}\right)^{*} \omega^{2}$ \\
\hline
\end{tabular}

The validity of this relationship is based on the following power condition:

Power on generator side $=$ Power on load side Hence,

$$
\begin{aligned}
\mathrm{V}_{\text {gen }} * \mathrm{I}_{\mathrm{gen}} & =\mathrm{V}_{\text {load }} * \mathrm{I}_{\text {load }} \\
\mathrm{M}_{\mathrm{i} \text {-gen }} * \mathrm{I}_{\text {gen }} & =\mathrm{M}_{\mathrm{i} \text {-load }} * \mathrm{I}_{\text {load }}
\end{aligned}
$$




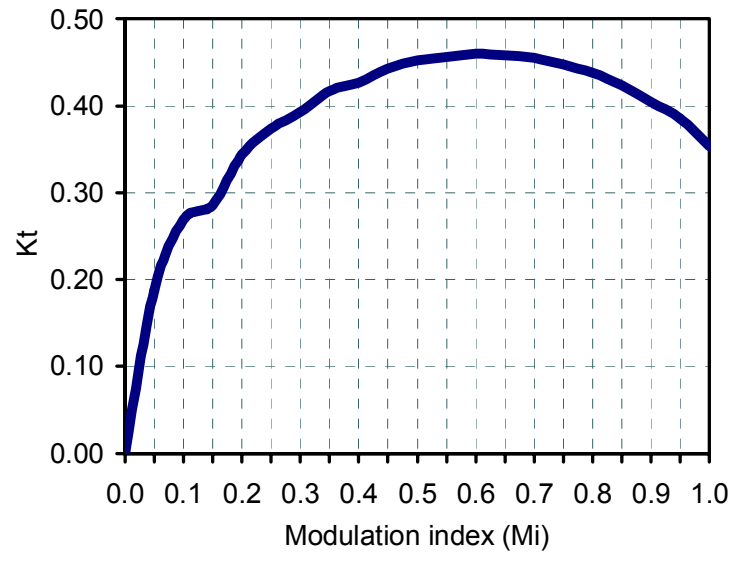

Figure 5. Normalized DC bus current ripple rms with constant output current

Therefore, to achieve a closer modeling of a real system, the above condition will have to be satisfied as appeared in the previous table 1 . Without loss of generality, we will assume $M_{L}=1$ in table 1 . The generated plot is given in Figure 6 which shows the linear relationship of the normalized current ripple as the generator frequency increases and the current on both sides of inverters adjusted to satisfy the power condition:

$$
\mathrm{K}_{\mathrm{t}}=250 \mathrm{e}-6 * \mathrm{f}_{\text {generator }}
$$

Furthermore, it can be verified from Figure 6 that the maximum normalized ripple current rms occurs at generator's frequency of $1600 \mathrm{~Hz}$, whose peak output current is the highest and so is its modulation index $\mathrm{M}_{\mathrm{i}}=1.0$.

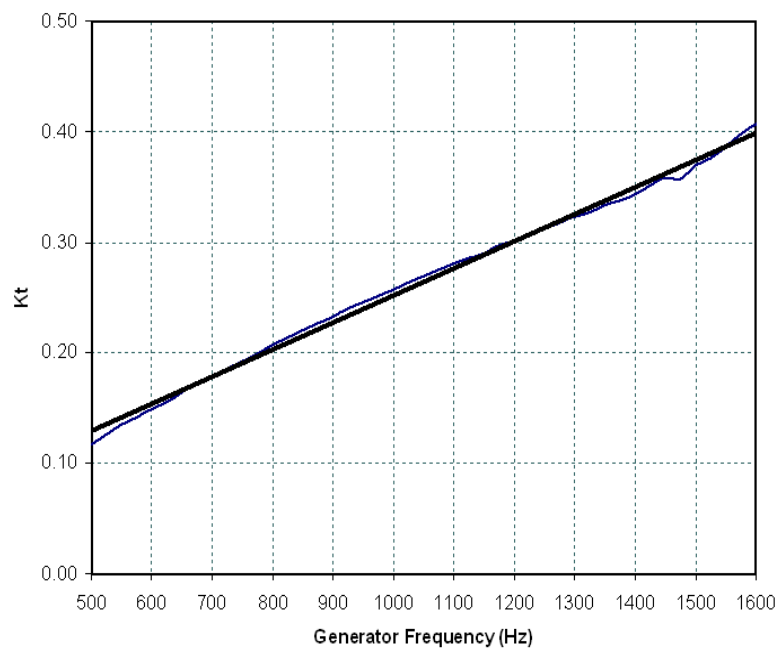

Figure 6. Normalized DC bus ripple current rms with adjusted output current and modulation index

\section{Combining Switching Frequencies}

Another study which may be of interest is to look at the effect of combining different switching frequencies of the two PWM's to the dc bus current ripple. The plot of this is given in Figure 7 where four different combinations are simulated. The results show that switching ratio of 1.0 , meaning $\mathrm{F}_{\text {switch- }}$ ${ }_{\text {low }} / \mathrm{F}_{\text {switch-high }}=1.0$, yields both the highest and the lowest ripple current at $90^{\circ}$ and $0^{\circ} / 180^{\circ}$ respectively. Ratio $r=0.67$ on the other hand gives the smallest maximum between $45^{\circ}$ to $135^{\circ}$, but yet a higher minimum.

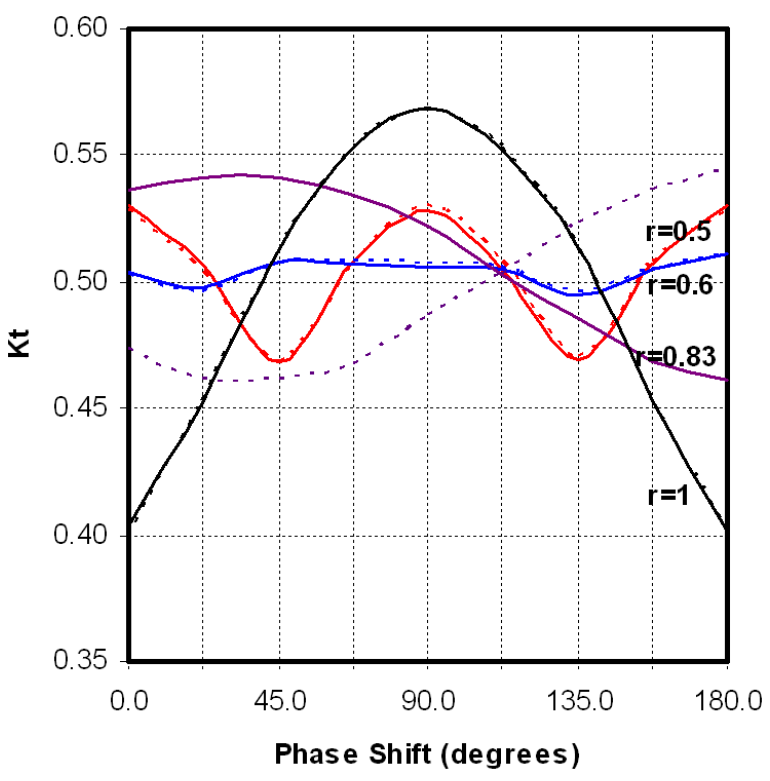

Figure 7. Normalized dc bus current ripple at different combination of switching frequencies

\section{Conclusions}

In this paper, the modeling and simulation of two PWM inverter systems connected through a dc bus has been presented. In particular, the modeling is aimed to study the effect of phase shifting and different combination of inverter's PWM switching frequencies to the dc bus current ripple connecting a PWM-based generator-load system. The simulation results indicate a linear behavior of current ripple upon varying generator's frequency. The simulation results also show that the largest rms current ripple was found to be at the modulation index of 1.0. When phase-shifting the two PWM inverters, the lowest current ripple was produced at $0^{\circ}$ or $180^{\circ}$. This is true for both in-phase or out-of-phase scenarios with equal switching frequency at both the generator and 
load side. By understanding how the two inverter systems impact the dc bus current ripple, proper sizing of the capacitor can then be fulfilled.

\section{References}

[1] Rashid, Muhammad H., Power Electronics Circuits, Devices, and Applications, New Jersey: Pearson Prentice Hall, 2004.

[2] Mohan, N., Undeland, T., and Robbins, W., Power Electronics: Converters, Application and Design, John Wiley and Sons Inc., 2002. 